\section{Las visitas papales a Cuba y su resonancia social y política}

\section{Papal visits to Cuba and their social and political resonance}

\author{
Beata Bereza ${ }^{1}$ \\ CENTRO DE ESTUDIOS LATINOAMRICANOS \\ UNIVERSIDAD DE VARSOVIA, POLONIA \\ $\triangle$ bebereza@uw.edu.pl
}

\section{RESUMEN}

Los viajes de Juan Pablo II en enero del 1998 y de Benedicto XVI en marzo del 2012 a Cuba, así como la visita del Papa Francisco en septiembre del 2015 tenían un objetivo común: fomentar los cambios positivos en la vida de los católicos en Cuba. Sin embargo, no cabe duda que las condiciones en que tuvieron lugar estas visitas eran diferentes. El propósito del artículo es analizar en qué medida la dinámica de las transformaciones sociales y políticas en Cuba estaba relacionada con el mensaje transmitido durante las visitas papales y las expectativas del pueblo cubano.

PALABRAS ClaVe: Juan Pablo II, Benedicto XVI, el papa Francisco, Cuba, peregrinaciones papales, Iglesia católica.

\begin{abstract}
The pilgrimages of John Paul II in January 1998 and Benedict XVI in March 2012 to Cuba, as well as the visit of Pope Francis in September 2015 had a common goal: to promote positive changes for the Catholics in Cuba. However there is no doubt that the conditions in which these visits took place were different. The purpose of the paper is to analyze to what extent the dynamics of social and political changes in Cuba were related to the message transferred during all papal visits and the expectations of the Cuban people.
\end{abstract}

KEYWORDS: John Paul II, Benedict XVI, Pope Francis, Cuba, papal pilgrimages, Catholic Church.

1 Graduada de la Cátedra de Estudios Ibéricos (actualmente: Instituto de Estudios Ibéricos e Iberoamericanos) de la Universidad de Varsovia, así como de Los Estudios Latinoamericanos de Postgrado del CESLA y de los Estudios de Postgrado en Edición del Instituto de Estudios Literarios de la Academia Polaca de Ciencias. Secretaria de redacción de las revistas científicas publicadas por el CESLA UW: el anuario "Revista del CESLA" y la revista trimestral "Ameryka Łacińska".
Anuario Latinoamericano Ciencias Políticas

y Relaciones Internacionales

vol. 3, 2016

pp. 53-69

DOI: 10.17951/al.2016.3.53 
América Latina: política y religión

\section{Introducción}

Las tres visitas papales a Cuba fueron, desde el establecimiento de las relaciones diplomáticas entre Cuba y Vaticano en 1935, los acontecimientos muy importantes tanto en la historia de la Iglesia cubana, como en la historia contemporánea de Cuba. El primer papa que visitó la isla fue Juan Pablo II (en 1998), al que siguió Benedicto XVI (en 2012), y por último, (en 2015) llegó a Cuba el papa Francisco.

Cada una de estas visitas tenía lugar en una realidad socio-política diferente. Y cada suscitaba muchas esperanzas. La situación más difícil (y no por ser primera) posiblemente tuvo que enfrentar Juan Pablo II, ya que llegaba a un país en que la vida religiosa estaba aún muy marginada en aquella época.

Juan Pablo II esperaba que sus palabras en Cuba tuvieran la misma resonancia y efectos palpables que su primer viaje a Polonia. ${ }^{2}$

\section{Visita de Juan Pablo II (21-25 de enero de 1998)}

La visita duró cinco días y se realizó entre el 21 y 25 de enero de 1998. El papa Juan Pablo II fue recibido en el aeropuerto de La Habana como jefe de Estado por el presidente Fidel Castro.

El elemento más patente en Cuba durante la primera visita papal fue una fuerte crisis económica causada por el desmoronamiento del "bloque socialista" y el colapso de la Unión Soviética. Esta época, que se convirtió en el penoso, oficialmente declarado "Período especial en tiempos de paz", se caracterizó también por el recrudecimiento de las sanciones de la administración de Washington (Ley Torricelli - embargo comercial y financiero de Cuba).

La pérdida de los vínculos económicos de Cuba con el CAME (Consejo de Ayuda Mutua Económica - Cuba formaba parte del Consejo entre los años 1972 y 1991) y, sobre todo, con la URSS, llevó al gobierno cubano a tomar ciertas medidas para enfrentar esta crisis. Una de ellas fue la modificación a nivel constitucional (enmienda del año 1992³) de las leyes concernientes la

2 Esta tuvo lugar en 1979, aun en la época del régimen autoritario desmantelado diez años más tarde. Sin embargo, la fundación del sindicato independiente "Solidaridad" en otoño del 1980 y la intensificación de su actividad en los meses siguientes fueron alentadas por las palabras de Juan Pablo II pronunciadas durante esta peregrinación. Durante la peregrinación en 1979 en la homilía en la Plaza de la Victoria en Varsovia (2.06.1979): Y grito, yo, hijo de tierra polaca, y al mismo tiempo yo: Juan Pablo II Papa, grito desde lo más profundo de este milenio, grito en la vigilia de Pentecostés: ¡Descienda tu Espíritu! ¡Descienda tu Espíritu! ;Y renueve la faz de la tierra! ¡De esta tierra! (Juan Pablo II, 1998).

3 Según la Constitución cubana del 1976, art. 54:

1. el Estado socialista, que basa su actividad y educa al pueblo en la concepción científica materialista del universo, reconoce y garantiza la libertad de conciencia, el derecho de cada uno a profesar cualquier creencia religiosa y a practicar, dentro del respeto a la ley, el culto de su referencia. 
propiedad privada para poder iniciar las reformas económicas (ante todo en la agricultura). El aislamiento político y, sobre todo, económico de Cuba causó una reducción drástica de los suministros de hidrocarburos procedentes de Rusia y, por consiguiente, la industria del país casi colapsó. Los cubanos aún recuerdan los apagones de largas horas, la sustitución del transporte público motorizado por los bicitaxis o coches de caballos. Y es cuando el gobierno cubano tomó la audaz decisión de iniciar, en 1993, una apertura a la inversión extranjera - principalmente en el sector turístico, introduciendo asimismo el sistema bimonetario y autorizando el empleo por cuenta propia en casi 150 profesiones. ${ }^{4} \mathrm{~A}$ toda esta situación se acumuló el descontento social que culminó en así llamada "crisis de los balseros" (1994).

Es la época cuando los disidentes ya forman (aunque poco numerosos) grupos de oposición política ${ }^{5}$ expresan sus opiniones críticas cada vez más abiertamente. Algunos aprovechan ya las amenidades electrónicas modernas como Internet. ${ }^{6}$

En la misma década a las filas de los críticos de la realidad se unen los hombres de arte y letras. Es cuando el novelista habanero Leonardo Padura empieza a publicar su ciclo de novelas policíacas (que conforman la tetralogía

2. La ley regula las actividades de las instituciones religiosas.

3. Es ilegal y punible oponer la fe o la creencia religiosa a la Revolución, a la educación o al cumplimiento de los deberes de trabajar, defender la patria con las armas, reverenciar sus símbolos y los demás deberes establecidos por la Constitución.

Constitución del 1976 con enmiendas del 1992. Artículo 55. El Estado, que reconoce, respeta y garantiza la libertad de conciencia y de religión, reconoce, respeta y garantiza a la vez la libertad de cada ciudadano de cambiar de creencias religiosas o no tener ninguna, y a profesar, dentro del respeto a la ley, el culto religioso de su preferencia. La ley regula las relaciones del Estado con las instituciones religiosas.

Artículo 19. El Estado reconoce la propiedad de los agricultores pequeños sobre las tierras que legalmente les pertenecen y los demás bienes inmuebles y muebles que les resulten necesarios para la explotación a que se dedican, conforme a lo que establece la ley. Los agricultores pequeños, previa autorización del organismo estatal competente y el cumplimiento de los demás requisitos legales, pueden incorporar sus tierras únicamente a cooperativas de producción agropecuaria. Además pueden venderlas, permutarlas o trasmitirlas por otro título al Estado y a cooperativas de producción agropecuaria o a agricultores pequeños en los casos, formas y condiciones que establece la ley, sin perjuicio del derecho preferente del Estado a su adquisición, mediante el pago de su justo precio.

El Estado apoya la producción individual de los agricultores pequeños que contribuyen a la economía nacional (Constitución... 1992).

${ }^{4}$ De hecho, la ley existió desde el año 1978 (cuando se dicta el Decreto Ley No. 14 sobre las actividades laborales por cuenta propia para ser ejercida por los trabajadores), sin embargo, renace en 1993 por Decreto-Ley 141 sobre el ejercicio del trabajo por cuenta propia, (Decreto-Ley $141 \ldots 1993)$.

5 En 1992, el más conocido crítico del régimen de Castro, Osvaldo Payá, trata de presentar, sin éxito, su candidatura a la Asamblea Nacional.

6 Y así, en 1994, empieza a publicarse on-line Cubanet - prensa independiente (https://www. cubanet.org/), y pocos meses más tarde surgen otras revistas electrónicas como, por ejemplo, Conexión Cubana (http://www.conexioncubana.net/).
Las visitas papales a Cuba y su resonancia social y política

Beata Bereza 
Dossier América Latina: política y religión de "Las cuatro estaciones") en que presenta la visión muy decadente de La Habana, donde los absurdos forman parte de la vida cotidiana de sus protagonistas. $^{7}$

En el transcurso de un lustro (1994-1999) la economía cubana fue sometida a reanimación y el año 1998, el de la visita papal, resultó ser el primer año de crecimiento para la economía cubana (Triana 1999).

En estas condiciones, con la visita de Juan Pablo II los cubanos abrigaban muchas esperanzas - las que fomentaba aún más la prensa extranjera.

El mismo papa, ya de regreso al Vaticano, en una de sus audiencias generales constató: "Espero para mis hermanos y hermanas en esa hermosa isla, que los frutos de este peregrinaje sean similares a los frutos de aquel peregrinaje a Polonia" (El Papa espera... 1998).

Sin embargo, el viaje a Cuba no pudo dar el mismo fruto que la visita a Polonia, ya que las condiciones socio-políticas eran muy diferentes. Sin entrar mucho en detalles, vale la pena destacar que tan sólo el componente religioso marca estas diferencias. La sociedad polaca era mayoritariamente católica, mientras que en Cuba el catolicismo funcionaba al margen de la vida de los cubanos. Según las estadísticas, el 60,19\% de la población es católica (Las cifras de la Iglesia... 2012), sin embargo, este catolicismo está fuertemente diluido por las religiones afrocubanas - entre ellas la santería es la que más seguidores tiene. Se calcula que el porcentaje de los seguidores de la santería puede llegar al 70\% de la población de la isla (La santería cubana s/f). Por lo tanto, es evidente que el creyente cubano promedio está asociado con más de una sola denominación religiosa. Y es obvio que el catolicismo convive en Cuba con los cultos afrocubanos enraizados en las religiones que trajeron los esclavos, y el esencial sincretismo de la isla hace que muchos cubanos combinen sus ritos santeros con la práctica del catolicismo. ${ }^{8}$

Entonces no será difícil comprender que existen en Cuba denominados de religiosidad múltiple. Es decir, personas que profesan más de dos religiones a la vez, algunas compatibles por sus orígenes. Hay creyentes que son a la vez Santeros y Católicos; Santeros, Paleros, Abakuá y Espiritistas, o Presbiterianos y a la vez Espiritistas, etc. Todo ello, aparentemente muy contradictorio, cuestionable y a la vez inaceptable por las jerarquías religiosas, pero lo cierto es que existe una rica variedad de identidades religiosas en Cuba (Richard, s/f).

Y en este contexto socio-cultural y económico le tocó realizar su visita al papa Juan Pablo II quien llegaba a esta isla caribeña con fama del actor

7 En una de las entrevistas Leonardo Padura, refiriéndose al "periodo especial”, dijo: "Eso sí que era una experiencia extrema. Mi esposa y yo resistimos, pero mucha gente no... Recuerdo también que era un momento de gran creatividad, que tenía mucho que decir". Por otro lado, en la misma entrevista constata: "Si va bien, los cubanos podrán vivir dignamente de su salario, que es una cosa que no ocurre ahora, según ha reconocido Raúl Castro" (Alemany, 2015).

8 Es el proceso que Fernando Ortiz llamó "transculturación” subrayando además su gran e incomparable dinámica: "Toda la escala cultural que Europa experimentó en más de cuatro milenios, en Cuba se pasó en menos de cuatro siglos...” (Ortiz 1983: 90). 
substancial de reformas políticas importantes en los países al otro lado del telón de acero y parece que muchos esperaban que su visita a la Cuba castrista trajera el mismo efecto. Una periodista de la agencia de noticias Reuters afirmaba:

El Papa había llegado a uno de los últimos bastiones comunistas del mundo con la reputación de ser el "ángel exterminador" del marxismo-leninismo tras haber jugado un papel clave en el derrumbe del comunismo soviético en Europa oriental. (Rama 2005)

Las esperanzas, sin embargo, se iban desvaneciendo poco a poco, aunque el mensaje transmitido por el papa Juan Pablo II en sus homilías fue alentador para los feligreses y muy incómodo para el régimen autárquico de Fidel Castro.

En su primer discurso, el de bienvenida, el papa pronunció las palabras más conocidas y más citadas en los medios:

Que Cuba se abra con todas sus magníficas posibilidades al mundo y que el mundo se abra a Cuba, para que este pueblo, que como todo hombre y nación busca la verdad, que trabaja por salir adelante, que anhela la concordia y la paz, pueda mirar el futuro con esperanza. (Juan Pablo II 1998)

Eran las palabras que los cubanos ansiaban escuchar. Por primera vez, desde hacía años, los actos religiosos se pudieron llevar a cabo fuera de las iglesias, y encima se transmitían por la televisión estatal. La misa en La Habana Juan Pablo II la celebra en la mítica Plaza de la Revolución donde no se abstuvo de hacer un llamamiento abierto a las autoridades:

El Estado, lejos de todo fanatismo o secularismo extremo, debe promover un sereno clima social y una legislación adecuada que permita a cada persona y a cada confesión religiosa vivir libremente su fe, expresarla en los ámbitos de la vida pública y contar con los medios y espacios suficientes para aportar a la vida nacional sus riquezas espirituales, morales y cívicas...

La conquista de la libertad en la responsabilidad es una tarea imprescindible para toda persona... Esta liberación no se reduce a los aspectos sociales y políticos, sino que encuentra su plenitud en el ejercicio de la libertad de conciencia, base y fundamento de los otros derechos humanos...

Para muchos de los sistemas políticos y económicos hoy vigentes el mayor desafío sigue siendo el conjugar libertad y justicia social, libertad y solidaridad, sin que ninguna quede relegada a un plano inferior, (Juan Pablo II 1998)

A la voz de Juan Pablo II se suma, en Santiago de Cuba, la del obispo de esta ciudad, Pedro Meurice quien en sus palabras de bienvenida, pronuncia-
Las visitas papales a Cuba y su resonancia social y política

Beata Bereza 
Dossier América Latina: política y religión das en presencia del vicepresidente de entonces Raúl Castro, exhorta al gobierno respetar las libertades de sus compatriotas y expresa una crítica aguda del régimen cubano:

Este es un pueblo que ha luchado largos siglos por la justicia social y ahora se encuentra, al final de una de esas etapas, buscando otra vez, cómo superar las desigualdades y la falta de participación.

Le presento, además, a un número creciente de cubanos que han confundido la Patria con un partido, la nación con el proceso histórico que hemos vivido en las últimas décadas, y la cultura con una ideología. (Saludo al Santo Padre... 1998)

La reacción de los cubanos fue inmediata. Éstas eran, indudablemente, las frases más esperadas:

El 24 de enero de 1998, en presencia de Raúl Castro y en una homilía pronunciada ante el Papa y decenas de miles de cubanos en la Plaza Antonio Maceo de Santiago de Cuba, vista con asombro y alegría además por millones de cubanos frente a sus televisores, Pedro Meurice Estiú desde ese preciso instante se convierte en un héroe para todos los cubanos dentro y fuera de Cuba. (Saludo al Santo Padre... 1998)

A partir de ese momento se ha vuelto el obispo Meurice el protagonista principal de la visita papal y el héroe verdadero de los disidentes dentro y fuera de Cuba. Cuando en 2001 falleció, el periodista Mauricio Vincent del diario español "El País" le rinde el homenaje:

Hay personajes que pasan a la historia por su trayectoria o por la semilla relevante que dejan. Otros permanecen y dejan huella por un arranque de coraje o unas palabras que los inmortalizan. Es el caso del arzobispo emérito de Santiago de Cuba Pedro Meurice Estiú, fallecido el 21 de julio a los 79 años, quien fuera protagonista de una de las escenas más recordadas del viaje que realizó a Cuba el papa Juan Pablo II invitado por Fidel Castro (...).

Algunos creyeron que su visita a la isla podía dar un empujón similar a la revolución de Fidel Castro, cosa que no ocurrió. Sin embargo, las palabras de Meurice y su nombre quedaron grabados a fuego en los manuales del anticastrismo. (Vincent 2011)

Aunque el interés por la visita de Juan Pablo II y las esperanzas por parte de la sociedad cubana (no sólo de los católicos) eran enormes, de hecho, los efectos, a la larga, no resultaron ser relevantes, aunque las primeras decisiones del gobierno cubano eran alentadoras; y parecía que el gobierno de Fidel Castro aflojó un poco su actitud hacia los disidentes excarcelando a un grupo de los presos. 
Tres semanas después de la visita, unos 300 detenidos, de los cuales más de 70 eran opositores al gobierno, fueron liberados, pero las esperanzas de más libertades civiles, mejores condiciones de vida y demandas concretas de la Iglesia, como el acceso a los medios de comunicación - controlados por el Estado - y a la educación, quedaron por el camino. (Rama 2005)

No obstante, pocos años después, la represalia aumentó, culminando con los arrestos de los detractores del gobierno cubanos en así llamada Primavera Negra de $2003^{9}$ y el consecuente recrudecimiento de las medidas económicas aplicadas por el gobierno de George Bush así como sanciones políticas de la Unión Europea contra el gobierno de Cuba. Ante tal situación crítica, el Episcopado cubano publicó la instrucción teológica pastoral "Sobre la presencia social de la Iglesia" en la cual deploró el retroceso en la situación de Cuba, así como reivindicó los derechos más elementales de los ciudadanos, expresando además su deseo de reconciliación y la necesidad de establecer un diálogo con el Estado (cit. Contreras 2013: 181).

Este mismo año, como respuesta a las limitaciones aplicadas por EE.UU. y la UE, Cuba ingresó, a finales de 2004, en la Alternativa Bolivariana para las Américas (ALBA) - una iniciativa integracionista firmada con el "líder de la Revolución Bolivariana en Venezuela”, el presidente Hugo Chávez.

En 2006, Fidel Castro, por cuestiones de salud, delegó sus principales funciones a su hermano, Raúl Castro, quien en poco tiempo anunció la necesidad de reformar, aunque siempre dentro del sistema socialista (Dembicz 2009: 26), el funcionamiento de la economía y sociedad cubanas, así como su disposición a dialogar con el nuevo presidente de Estados Unidos (2009) - Barack Obama. Es la época cuando Cuba dejó de ser vista "a través de los lentes de la confrontación Este-Oeste" y, además, se la consideró "un actor responsable y legítimo en el marco regional, independientemente de su sistema político y de las dificultades que pueda atravesar en el proceso de «actualización» del mismo" (Serbin 2013: 204).

Años más tarde, cuando para el viaje a Cuba se preparaba Benedicto XVI, uno de los disidentes, Óscar Elías Biscet ${ }^{10}$ sostenía que la visita del papa a Cuba era un "gran error político y estratégico", ya que en 1998 "...mientras estaba Juan Pablo II en Cuba, el gobierno estaba preparando las leyes penales para

9 La presencia del papa en Cuba no desalentó al gobierno cubano a reprimir el movimiento de oposición, o más bien núcleos de los detractores del gobierno de los Castro. En marzo de 2003 fueron arrestados 75 activistas de los derechos humanos y condenados a largas penas de cárcel (entre los 6 y los 25 años) por realizar actos "contra la independencia y estabilidad territorial del Estado" y "socavar los principios de la Revolución". La represalia frente al grupo de 75 opositores dio origen al término de la Primavera Negra. Es cuando nació el movimiento de Las Damas de Blanco, formado por las esposas y madres de los arrestados (La Primavera Negra... s/f).

${ }^{10}$ Elías Biscet, médico de profesión, fue una de las víctimas de la Primavera Negra de 2003; condenado a 25 años de prisión, considerado preso de conciencia por Amnistía Internacional, fue uno de los disidentes que rechazaron exiliarse en España tras su excarcelación.
Las visitas papales a Cuba y su resonancia social y política

Beata Bereza 
Dossier América Latina: política y religión sancionar y reprimir al pueblo cubano" (Disidente considera... 2012). A la hora de la segunda visita papal a Cuba, la de Benedicto XVI, Biscet esperaba:

Me gustaría que el papa le exigiera al gobierno que hiciera elecciones libres y democráticas para que el pueblo se expresara libremente y que existiera el multipartidismo, para que todas las personas se sientan representadas en sus ideas. (Disidente considera... 2012)

De esta forma y en el ambiente de grandes esperanzas, sobre todo en cuanto a que el papa abordara el problema de los derechos humanos, se estaba preparando el terreno para la visita del papa Benedicto XVI prevista para el marzo del 2012.

\section{La visita de Benedicto XVI (26-28 de marzo de 2012)}

La visita de Benedicto XVI fue la más corta de las visitas papales - duró apenas tres días (Juan Pablo II pasó en Cuba cinco días, el papa Francisco - cuatro) y se desarrolló catorce años después de la peregrinación de su predecesor, en un contexto socio-político diferente a la realidad de la época de los finales de los noventa. Un ambiente en que la Iglesia católica se ha vuelto un artífice de la reconciliación, actuando como mediador entre el gobierno cubano y los familiares de los disidentes presos. El hecho que suscitó polémicas (o hasta críticas $^{11}$ ) entre los representantes de los disidentes cubanos.

En ocasión de la visita papal hubo obviamente indultos; casi 3000 presos liberados antes de la visita de Benedicto XVI, entre ellos unos 135 presos políticos excarcelados como resultado del diálogo entre los obispos cubanos y el presidente Raúl Castro.

Sin embargo, la represión política junto con el colapso de la economía cubana de la planificación centralizada tuvieron las consecuencias sociales muy profundas. "Alrededor del $15 \%$ de la población se ha marchado al exilio (...). Las severas condiciones de vida provocaron una crisis demográfica sin precedentes (...). A la emigración se ha sumado la caída de tasas de fertilidad y natalidad” (Unión Liberal Cubana 2012). A estos fenómenos se agregaron igualmente la estrategia del gobierno de seguir conservando el modelo centralizado y estatal de la economía, aunque con pequeñas excepciones, como por ejemplo, la entrega de tierras en usufructo (ya desde el año 2008). No obstante, la dinámica de los indicadores económicos seguía manteniéndose al nivel preocupante; la tasa de crecimiento del PIB, aunque subió levemente en el año 2012, apenas alcanzó el 3\% (ONEI 2012). ${ }^{12}$

\footnotetext{
${ }^{11}$ La actitud de la Iglesia cubana fue criticada por algunos disidentes.

12 El reconocido economista cubano Carmelo Mesa-Lago (2008) advirtió que CEPAL desde 2005 no publicaba los indicadores del PIB cubano, considerándolos poco fiables. Además, el alza
} 
Benedicto XVI inició su visita en Santiago de Cuba con una misa celebrada en la Plaza Antonio Maceo. En su homilía destacaba: "Con las armas de la paz, el perdón y la comprensión, luchen para construir una sociedad abierta y renovada, una sociedad mejor, más digna del hombre" (Benedicto XVI 2012).

En la siguiente misa, celebrada en la capitalina Plaza de la Revolución, el papa Benedicto XVI dejó el mensaje de defensa de las libertades, criticó el bloqueo de Estados Unidos contra la isla y abogó por la reconciliación de los cubanos de dentro y fuera del país:

El derecho a la libertad religiosa, tanto en su dimensión individual como comunitaria, manifiesta la unidad de la persona humana, que es ciudadano y creyente a la vez. Legitima también que los creyentes ofrezcan una contribución a la edificación de la sociedad. Su refuerzo consolida la convivencia, alimenta la esperanza en un mundo mejor, crea condiciones propicias para la paz y el desarrollo armónico, al mismo tiempo que establece bases firmes para afianzar los derechos de las generaciones futuras. (Palabras de Benedicto... 2012)

Tuvieron una resonancia fuerte las palabras pronunciadas en presencia del presidente Raúl Castro, en las que Benedicto XVI exhortó a construir una sociedad renovada en que nadie se vea impedido "por la limitación de sus libertades fundamentales".

Y ya al final de su visita, se pudo escuchar el mensaje de la reconciliación de todos los cubanos: "que Cuba sea la casa de todos y para todos los cubanos" y terminó con las palabras emotivas "Hasta siempre, Cuba..." (Palabras de Benedicto... 2012).

Los obispos cubanos, por su lado, siguieron la línea del magisterio social, inspirados en el mensaje de Benedicto XVI y también el de Juan Pablo II: “al Gobierno le recuerdan «su obligación de procurar el bien de todos», teniendo en cuenta «los justos intereses de cada grupo que compone nuestra sociedad». Esto se traduce (...) en sustituir definitivamente el Estado paternalista por un Estado participativo..." (Los obispos cubanos... 2013).

Y por último, resumiendo los efectos de la visita de Benedicto XVI, vale la pena recordar que, en una reunión en privado con el presidente Raúl Castro, el papa Benedicto XVI le entregó al presidente cubano una lista de presos políticos, pidiendo su liberación, y también instó a Raúl Castro que se declarara día festivo cada año el Viernes Santo. Castro se adhirió a la solicitud de Benedicto XVI y desde entonces los cubanos tienen un día festivo más.

A pesar de los efectos obvios de la intervención de Benedicto XVI, como la excarcelación de los presos o la declaración por el gobierno el Viernes Santo
Las visitas papales a Cuba y su resonancia social y política

Beata Bereza

de los números no se tradujo automáticamente en un mejoramiento de las condiciones de vida de los cubanos. 
Dossier América Latina: política y religión como día festivo, parece que la visita de Benedicto XVI pasó un poco desapercibida. Lo que no fue el caso de la visita del papa Francisco, quien, a pesar de formular su mensaje de forma más suave y conciliador que sus predecesores, se ha vuelto, por cuatro días, el protagonista principal de los medios de comunicación en el país.

\section{El papa Francisco (19-22 de septiembre de 2015)}

La gran ventaja del viaje del papa Francisco a Cuba fue el hecho de que llegaba a la isla como un latinoamericano: "Este Papa ha revolucionado la filosofía católica y se ha puesto al lado de los explotados. Se ha vuelto un icono. Es el Papa de América" (Llano 2015).

Y también los antecedentes de la visita del papa Francisco fueron muy prometedores. Primero, durante el encuentro del papa Francisco con el presidente Raúl Castro aún en el Vaticano (que tuvo lugar el 10 de mayo de 2015), cuatro meses antes de la visita del papa a Cuba, el presidente cubano hizo una declaración sorprendente: "Leo todos los discursos del papa y si el papa continúa hablando así volveré a rezar y regresaré a la Iglesia, y no lo digo en broma" (Castro agradece... 2015). Y luego, una semana antes de la visita del papa Francisco, el diario oficial "Granma" informó sobre la decisión del Consejo de Estado de la República de Cuba de indultar a 3522 presos:

En ocasión de la visita de Su Santidad, el Papa Francisco, y al igual que aconteció cuando nos visitaron los Sumos Pontífices Juan Pablo II y Benedicto XVI, acordó indultar a 3522 sancionados, teniendo en cuenta la naturaleza de los hechos por los que fueron penados, su comportamiento en prisión, el tiempo de cumplimiento de la sanción y razones de salud. (Acordó Consejo de Estado... 2015)

Fue la mayor excarcelación en la historia de la Cuba castrista. Berta Soler, la líder de las Damas de Blanco, afirmó que esta decisión del gobierno "supera en parte las expectativas", sin embargo, por otro lado hizo una advertencia: "el Gobierno cubano es muy astuto y no será la primera vez que antes de anunciar una excarcelación de presos como ésta, se dedica meses antes a encarcelar a gente por delitos menores para luego soltarlos e inflar las cifras" (Disidentes señalan... 2015). Por otro lado, José Daniel Ferrer, líder de la Unión Patriótica de Cuba (UNPACU), señaló que ninguno de los 21 presos políticos de su organización está en la lista.

Como pasó con las dos visitas anteriores, también esta vez los cubanos la esperaban con muchas ilusiones.

Es evidente que la visita del papa Francisco tuvo lugar en un país diferente al país visitado por sus antecesores. El proceso de cambios seguía. Obviamente, al ritmo pautado por el gobierno y siempre dentro del marco de la 
revolución cubana (La Constitución cubana, cuando habla de las libertades, las condiciona: "siempre que su contenido no sea contrario a la Revolución"; Constitución... 1992). Con la explosión del uso, en los últimos años, de los medios electrónicos (y todo a pesar de los límites en el acceso a Internet) la brecha generacional se está profundizando. La nueva generación que está creciendo se volvió más crítica y más impaciente, ansiosa de cambios y llena de cierto optimismo:

No sé si alguien aun crea en milagros papales respecto a nosotros. A diferencia de su antecesor, llega en un momento en que Cuba se apresta a un cambio generacional que traerá como cola un cambio sistémico. (...) Un proyecto agotado en sí mismo que en el camino agotó también la capacidad de los ciudadanos para imaginar prosperidad al pausado paso de la llamada "actualización del modelo". (Coyula 2015)

Los católicos esperaban que gracias a la visita del "misionero de la misericordia" se reforzara la base (muy débil) social de la Iglesia cubana.

Otro factor importante fue el hecho de que el papa Francisco llegó a Cuba con fama del "papa del deshielo", o sea, como autor discreto pero importante de las mediaciones entre Cuba y Estados Unidos, que culminaron en julio 2015 con la reapertura de las respectivas embajadas en Cuba y Estados Unidos, lo que significó el restablecimiento de relaciones entre ambos países, rotas hacía más de medio siglo (en 1961).

Las palabras más citadas de los discursos (que eran siete; dos de ellos improvisados) del papa Francisco, pronunciados durante esta peregrinación, fue la frase: "Quien no vive para servir, no sirve para vivir", pronunciada el 20 de septiembre, en la legendaria Plaza de la Revolución en la Habana. A la que siguió el mensaje a los jóvenes: "que sepamos acoger y aceptar al que piensa diferente". (Papa Francisco en Cuba 2015)

\section{Conclusiones}

El papa Juan Pablo II quien contribuyó decisivamente a la democratización de los países hasta entonces satélites de la URSS fracasó en la Cuba castrista.

A veces uno cae en la tentación de comparar las dos peregrinaciones del papa Juan Pablo II: la del 1979 a la República Popular de Polonia y en 1998 a la Cuba castrista. Seguramente las intenciones por parte del Vaticano eran similares: impulsar los cambios democráticos en ambas regiones. Sin embargo, no se puede comparar la situación socio-política de Polonia y de Cuba. El fervor religioso era muy diferente, como también fue diferente el movimiento de oposición. En Polonia, en poco tiempo se llegó a formular postulados y unir bajo los mismos ideales y el mismo estandarte de la "Solidaridad" a millones
Las visitas papales a Cuba y su resonancia social y política

Beata Bereza 
Dossier América Latina: política y religión de trabajadores, mientras que en Cuba los disidentes forman grupos pequeños carecientes, de hecho, de un apoyo social significativo.

El mismo papa Juan Pablo II al cabo de varios años consideró su decisión de viajar a Cuba como su mayor error político (cit. Jordá 2014). Lo admitió ya que se dio cuenta de que su visita no cumplió las expectativas de impulsar de forma más decidida los cambios democráticos en este país caribeño. Aunque tampoco se puede subestimar el papel de su visita ¿No fue, acaso, la presencia del papa en Cuba en 1998 la que alentó a los detractores del gobierno de Castro a formular, este mismo año, un proyecto de reforma política conocido como Proyecto Varela? ${ }^{13}$

Juan Pablo II en sus doce discursos pronunciados durante cinco días de visita a Cuba la palabra "libertad" la pronuncia en 49 ocasiones y en 29 clama por la "justicia”, mientras que en los discursos de Benedicto XVI (que eran cinco) nueve veces aparece la palabra "libertad" y en las homilías de Francisco tan sólo tres veces la "libertad" y apenas dos veces - la "justicia”. Lo que significa que el más comprometido e intrépido en su discurso fue Juan Pablo II.

La visita de Benedicto XVI a Cuba fue la más corta (duró apenas tres días), pero en su dimensión política tuvo una repercusión marcada por la excarcelación más grande que hubo en Cuba hasta entonces. El Papa Francisco fue más discreto en su mensaje social. Por lo cual muchos estaban desilusionados. "Pese a la imagen que se ha querido transmitir no supuso ningún aporte positivo para la Isla. (...) A pesar de que ha participado una gran parte del pueblo de Cuba, pero la mayor parte que lo ha hecho ha sido obligada a participar por el Gobierno" (Periodista cubano... 2015). Muchos también le reprocharon a Francisco el hecho de no haberse reunido con la disidencia cubana. Y no importaba que tampoco lo hicieran Juan Pablo II ni Benedicto XVI.

Si evaluamos los efectos de las visitas papales a Cuba, cabe destacar que, sin duda alguna, la visita del papa Francisco tuvo la resonancia mediática más fuerte - relato minuto a minuto en el diario "Granma", así como la presencia de Raúl Castro en todos los actos litúrgicos.

“Granma”, el órgano oficial del Comité Central del partido, además de contar detalladamente cada instante de la visita del papa Francisco a Cuba, publicó una edición especial en color dedicada a este acontecimiento. Lo que los lectores recibieron con mucha satisfacción, pero también con la ansiedad de siempre en este país de escaseces crónicas:

Esperamos que esa edición especial llegue al pueblo a través de los estanquillos de prensa y que no suceda como con otras publicaciones que se pierden durante la travesía y jamás llegan a su destino final y después aparecen por las calles a un mayor precio de venta. (Edición Especial... 2015)

${ }^{13}$ Félix Varela (1788-1853) fue un sacerdote, maestro, escritor, filósofo y político cubano que tuvo un importante desempeño en la vida intelectual, política y religiosa en la Cuba de la primera mitad del siglo XIX. Considerado uno de los forjadores de la nación cubana. 
De entre los discursos papales, el mensaje de Juan Pablo II fue seguramente el más fuerte, comprometido e intransigente (y, por lo tanto, más difícil y amargo para el gobierno); con el claro llamamiento a respetar los derechos de los ciudadanos. Fidel Castro no tuvo reparos en responderle al papa con contundencia:

Era cruelmente injusto que su viaje pastoral fuese asociado a la mezquina esperanza de destruir los nobles objetivos y la independencia de un pequeño país bloqueado y sometido a una verdadera guerra económica hace ya casi 40 años. Cuba, Santidad, se enfrenta hoy a la más poderosa potencia de la historia, como un nuevo David, mil veces más pequeño, que con la misma honda de los tiempos bíblicos, lucha para sobrevivir contra un gigantesco Goliat de la era nuclear que trata de impedir nuestro desarrollo y rendirnos por enfermedad y por hambre. (Palabras de despedida... 1998)

A pesar de que el gobierno inició los cambios económicos, parece que en lo político no cedió nada; más aún - la retórica en contra de los detractores del régimen endureció. Los medios oficiales les llaman a los disidentes "mercenarios de Estados Unidos". A los blogueros críticos de la realidad cubana se les califica como "cibermercenarios". A la bloguera cubana más conocida, Yoani Sánchez, la llaman "bloguera mercenaria" o "agente 00Y".

Las tres visitas papales a Cuba constituyeron los acontecimientos importantes no sólo para la población católica del país, ya que cada de estas peregrinaciones tenía una dimensión que traspasaba lo religioso.

La presencia de Raúl Castro en todos los actos religiosos durante la visita del papa Francisco fue significativa - algunos la interpretaron como muestra del respeto hacia el huésped. Para muchos era más bien un abuso o, por lo menos, una incongruencia. El hecho que Yoani Sánchez resumió acertadamente con un agudo sarcasmo:

Los excesos de incienso de estos días no han gustado a muchos. "Esto va de lo sublime a lo ridículo", me comentó un militante del Partido Comunista de 63 años, que vive en mi edificio. "Del ateísmo al servilismo religioso", agregó en alusión a la actitud de las autoridades cubanas y la transmisión de misas completas en los medios nacionales. "Ahora sólo nos falta escuchar el próximo discurso público de Raúl Castro para comprobar si también ha sustituido el belicoso ¡Patria o muerte! por el conciso ¡Amén!”. (Sánchez 2015)

A pesar de todas las dificultades, parece que la apertura de Cuba, tan soñada por Juan Pablo II, se vuelve lentamente realidad en la época del papa Francisco. ${ }^{14}$ Empero, a pesar de que los procesos de cierta apertura (o ajus-

${ }^{14}$ Actualmente "[1]os cubanos que fueron de visita en julio y lo que va de agosto a los Estados Unidos, principalmente a Miami y Tampa, tuvieron que esperar para lograr la reservación
Las visitas papales a Cuba y su resonancia social y política

Beata Bereza 
Dossier América Latina: política y religión tes) que se desenvuelven en Cuba desde los años noventa coincidieron con las peregrinaciones papales a la isla, sería excesivo declarar que los cambios que se producen actualmente en Cuba fueron consecuencia directa de estas visitas. Ni siquiera fueron catalizador de estos cambios. Y, con certeza, el actor político que más ganó con estas visitas fue el gobierno de Cuba. Resultó ser una simple, pero muy eficaz, estrategia para mejorar la imagen de Cuba en el mundo.

Y no fue la relevancia del mensaje transmitido por los papas a los cubanos el factor decisivo para los cambios en la economía del país y, por lo tanto, en la calidad de vida de muchos cubanos. Corresponde vincular más este impacto a las remesas enviadas por sus familiares desde el extranjero ${ }^{15}$ y las visitas de los cubanoamericanos a la isla ${ }^{16}$, así como a un instrumento potente en la formación de la nueva generación de cubanos que es Internet. ${ }^{17}$

Para muchos cubanos las visitas papales supusieron sólo algunos cambios "cosméticos" y a lo mejor... la recuperación de dos días festivos.

Además, a muchos cubanos no católicos les desilusionó la falta del diálogo ecuménico - el diálogo que incluyera también a las denominaciones afrocubanas. Vale la pena señalar que, por ejemplo, a los practicantes de la santería les parecía una postura parcial la de subrayar en los discursos, por un lado, el papel de la Iglesia católica en la formación de la nación y, por otro, silenciar el componente africano, tan presente en la vida cotidiana de Cuba (Duany 2009).

Como el discurso crítico y, como ya se había mencionado, más comprometido de Juan Pablo II y de Benedicto XVI no dio resultados esperados, Francisco optó por la retórica más conciliadora.

Y aunque parece todavía prematuro evaluar los efectos de su visita a Cuba, se puede esperar que esta visita tenga un impacto más significativo que las visitas de sus antecesores. El papa Francisco con su mensaje muy humano, más centrado en las relaciones entre los prójimos y menos político quizá logre más. No cabe duda de que ya se ha vuelto, aunque fuese en contra de su voluntad, el mejor portavoz de Cuba (y por consiguiente del gobierno cubano representado por Raúl Castro).

de regreso, porque los 12 vuelos diarios desde estas dos ciudades estaban cubiertos" (Avalancha de turistas... 2014).

${ }^{15}$ Remesas - desde el año 1992 crecimiento rápido en 1995 alcanza 600 millones USD para llegar en 2002-2003 a un valor de 1200 millones USD al año. El pasado año 2014 desde EE.UU. fueron enviados 2780 millones USD, que junto con los 3506 millones USD de remesas en especie sumaron 6286 millones USD (Avalancha de turistas... 2014).

${ }^{16}$ Desde la década de los noventa el número de residentes estadounidenses de ascendencia cubana estaba creciendo (desde 2600 en 1990) hasta superar 120 mil viajeros en los años 19982003, para bajar en el año 2004 cuando el gobierno de George W. Bush impuso las restricciones sobre estas visitas como una parte de las sanciones contra Cuba (Duany 2009: 197).

${ }^{17}$ En 1996, Cuba accede a Internet vía satélite. En 2011, se concluyó el cable submarino de fibra óptica entre Venezuela y Cuba (entró en servicio a inicios de 2013). 


\section{Bibliografía}

Acordó Consejo de Estado indultar a 3522 sancionados, "Granma", 10.09.2015, disponible en: http://www.granma.cu/cuba/2015-09-10/acordo-consejo-de-estado-indultar-a-3-522sancionados, fecha de consulta: 22.10.2015.

Alemany L., Leonardo Padura: "Me quedé en Cuba para escribir", "El Mundo", 11.03.2015, disponible en: http://www.elmundo.es/cultura/2015/03/11/54fdcd73268e3eb91a8b4577. html, fecha de consulta: 25.10.2015.

Avalancha de turistas cubano-americanos, "Cubanet", 20.08.2014, disponible en: https:// www.cubanet.org/opiniones/avalancha-de-turistas-cubano-americanos/, fecha de consulta: 28.10.2015.

Benedicto XVI (2012), Homilías 2012, disponible en: https://w2.vatican.va/content/ benedict-xvi/es/homilies.index.html\#homilies, fecha de consulta: 22.10.2015]

Castro agradece al papa por el deshielo Cuba-EEUU y preparó su viaje a La Habana, Agencia EFE, 10.05.2015, disponible en: http://www.efe.com/efe/espana/portada/castro-agradeceal-papa-por-el-deshielo-cuba-eeuu-y-preparo-su-viaje-a-la-habana/10010-2608583, fecha de consulta: 22.10.2015.

Las cifras de la Iglesia en México y Cuba, "Vida Nueva", 20.03.2012, dosponible en: http:// www.vidanueva.es, fecha de consulta: 25.10.2015.

Constitución de la República de Cuba, 1992, disponible en: http://www.cubanet.org/htdocs/ ref/dis/const_92.htm, fecha de consulta: 22.10.2015.

Contreras D. (2013), El papel de la Iglesia católica en el futuro de Cuba: su misión ante la sociedad y el Estado, en: Cuba: ¿quo vadis?, K. Dembicz (ed.), CESLA, Warszawa, pp. 169-193.

Coyula R., Voces desde Cuba: Los cambios cosméticos que traen los Papas a Cuba, "BBC Mundo". 17.09.2015, disponible en: http://www.bbc.com/mundo/blogs/2015/09/150917_ voces_desde_cuba_regina_coyula_papa_francisco_visita, fecha de consulta: 22.10.2.2015.

Decreto-Ley no 141 de 8 de septiembre de 1993 sobre el ejercicio del trabajo por cuenta propia, "Gaceta Oficial Extraordinaria", no 5, 08.09.1993.

Dembicz A. (2009), Cronología cubana, en: Cuba 2009. Reflexiones en torno a los 50 años de la revolución de Castro, A. Dembicz (ed.), CESLA UW, Warszawa, pp. 13-27.

Disidente considera la visita del Papa a Cuba un "gran error político", "El Universal", 16.02.2012, disponible en: http://www.eluniversal.com/, fecha de consulta: 1.11.2015.

Disidentes señalan la ausencia de presos políticos en la lista de indultados, "Diario de Cuba", 11.09.2015, disponible en: http://www.diariodecuba.com/cuba/1441995213_16863.html, fecha de consulta: 22.10.2015.

Duany J. (2009), La diáspora cubana desde una perspectiva transnacional, en: Cuba 2009. Reflexiones en torno a los 50 años de la revolución de Castro, A. Dembicz (ed.), CESLA UW, Warszawa, pp. 189-207.

Edición Especial de "Granma" dedicada a la reciente visita del Papa Francisco, "Granma", 30.09.2015, disponible en: http://www.granma.cu, fecha de consulta: 22.10.2015.

Jordá C., La Cuba de Castro: la tiranía frente a la que fracasó Juan Pablo II, "Libertad Digital Latinoamericana", 18.12.2014, disponible en: http://www.libertaddigital.com/ internacional/latinoamerica/2014-12-18/la-cuba-de-castro-la-tirania-frente-a-la-quefracaso-juan-pablo-ii-1276536389/, fecha de consulta: 1.11.2015.
Las visitas papales a Cuba y su resonancia social y política

Beata Bereza 
Dossier América Latina: política y religión
Juan Pablo II (1998), Homilías 1998, disponible en: http://w2.vatican.va/content/johnpaul-ii/es/.html, fecha de consulta: 25.10.2015.

Llano P. de,Loscubanosesperanal Papa del deshielo, “El País”, 18.09.2015, disponible en: http:// internacional.elpais.com/internacional/2015/09/18/actualidad/1442533538_290608.htm, fecha de consulta: 1.11.2015.

Mesa-Lago C. (2008), La economía y el bienestar social en Cuba: situación actual. Debate sobre las reformas y políticas de Raúl Castro, "Revista Socio-Cultural Convivencia", no 5.

Los obispos cubanos reclaman un futuro democrático para la isla, "Religión digital", 15.09.2013, disponible en: http://www.periodistadigital.com/religion/america/2013/09/15/ los-obispos-cubanos-reclaman-un-futuro-democratico-para-la-isla-religion-iglesiaamerica-dios-.shtml.

ONEI - Oficina Nacional de Estadísticas e Información (2012), Anuario Estadístico de Cuba, La Habana.

Ortiz F. (1983), Contrapunteo cubano del tabaco y el azúcar, Editorial de Ciencias Sociales, La Habana.

Palabras de Benedicto XVI en la ceremonia de despedida en el aeropuerto de La Habana "Vida Nueva", 29.03.2012, disponible en: http://www.vidanueva.es/2012/03/29/, fecha de consulta: 22.10.2015.

Palabras de despedida del Presidente Fidel Castro, 25.01.1998, disponible en: http://www. catolicos.org/visita.htm, fecha de consulta: 22.10.2015]

El Papa espera que Cuba imite a Polonia, "La Nación", 29.01.1998, disponible en: http:// www.lanacion.com.ar/86581-el-papa-espera-que-cuba-imite-a-polonia, fecha de consulta: 25.10.2015.

Papa Francisco en Cuba, disponible en: http://papafranciscoencuba.cubaminrex.cu/ articulos/, fecha de consulta: 1.11.2015.

Pérez Villanueva O. E. (2013), La actualización del modelo económico en Cuba: una necesidad impostergable, en: Cuba: ¿quo vadis?, K. Dembicz (ed.), CESLA, Warszawa, pp. 15-37.

Periodista cubano contó el lado oscuro de la visita del Papa a la isla, 29.09.2015, disponible en: http://www.perfil.com/politica/Periodista-cubano-conto-el-lado-oscuro-de-la-visitadel-Papa-a-la-isla-20150925-0016.html, fecha de consulta: 09.10.2015.

La Primavera Negra de 2003, "Las Damas de Blanco", disponible en: http://www.damasdeblanco. com/primavera/primavera2003.asp, fecha de consulta: 1.11.2015.

Rama A., Cuba: el "muro" que Juan Pablo II no pudo derribar, "Invertia", 2.04.2005, disponible en: http://www.invertia.com/noticias/articulo-final.asp?idNoticia=1255501, fecha de consulta: 1.11.2015.

Roselló R., Santería. Un crisol de religiones, disponible en: http://www.conexioncubana.net/ santeria/3793-un-crisol-de-religiones, fecha de consulta: 22.10.2015.

Saludo al Santo Padre pronunciado por Mons. Pedro Meurice antes de comenzar la Santa Misa en la Arquidiócesis de Santiago de Cuba. (Enero 24, 1998), disponible en: http://www. catolicos.org/visita.htm, fecha de consulta: 30.11.2015.

Sánchez, Y., "Raúl Castro, el monaguillo", Generación Y, 22.09.2015, disponible en: http:// www.14ymedio.com/blogs/generacion_y/Raul-Castro-monaguillo_7_1857484234.html, fecha de consulta: 28.10.2015.

La santería cubana, "Conexión Cubana", disponible en: http://www.conexioncubana.net/ general/la-religion-en-cuba/santeria/, fecha de consulta: 22.10.2015. 
Serbin A. (2013), La política exterior de Cuba en un mundo multipolar, "Anuario CEIPAZ", no 5, pp. 187-220.

Triana Cordoví J. (1999), Cuba 1998: la reanimación económica y las restricciones del crecimiento, trabajo presentado en el Seminario Anual del Desempeño de la Economía Cubana, Centro de Estudios de la Economía Cubana, La Habana, marzo.

Unión Liberal Cubana, Cuba: situación sociopolítica y económica, "Revista Encuentro", 06.04.2012.

Vincent M., Pedro Meurice, el azote de la Iglesia cubana al régimen, "El País", 31.07.2011, disponible en: http://elpais.com/diario/2011/07/31/necrologicas/1312063202_850215.html, fecha de consulta: 30.11.2015.
Las visitas papales a Cuba y su resonancia social y política

Beata Bereza 